to spend a number of years in the practice of something he does not expect to follow. With the present system of dental education, a student cannot afford to spend any more time than is necessary before he specializes. After he has finished his college course and has decided that he is going to specialize, he should immediately begin the study of that subject in the most approved way, so that he will be prepared to render some return to society before he is an old man. It is a waste of time and energy to compel a man to practice a number of years before allowing him to take up a specialty.

The oral surgeons of the future will no doubt be men who have had both medical and dental training if they are to give the specialty the standing it should have. Up to the present time postgraduate teaching in oral surgery has not made the advances that it has in orthodontia. This may be because methods have not been standardized, the literature is not in good shape and societies of oral surgeons have not been organized. Such courses in oral surgery as have been offered have not been satisfactory. With the knowledge gained by a few men who did actual oral surgery during the war, it should be possible to so standardize different methods that oral surgery may be more successfully taught than it has been in the past. We look for much progress in this specialty during the next few years.

There may be too much of a tendeney for specialties to spring up among the dental and medical professions, but regardless of that evil, we believe the public is receiving better service because of specializing, and if that is true, a good purpose has been accomplished.

\title{
Are the Specialists in Orthodontia Derelict in Their Duty Toward the Dental Profession?
}

$\mathrm{T}$ HE year 1921 appears upon the shifting scenes of time at a period when never before in its history, has the practice of dentistry been more attractive and interesting nor has it ever made history and advancement with such rapid strides, as at this time.

The dental profession is fairly clamoring for information and advancement in all of the various departments of dentistry, eager to learn, ambitious to be "up to the minute" and the field is being more and more divided into specialties. Orthodontia, at one time standing alone as a specialty in dentistry, does not now enjoy this distinction; on the other hand it has become only one of the many departments which may be specialized, or may be practiced in conjunction with general work.

The above is all evidenced by the enrollments in the study clubs of our large cities, many of them having a long waiting list, men fairly standing in line, as it were, to procure modern instruction in conductive anesthesia, removable crown and bridge, prosthesis, as well as many other subjects which seem to be popular at this time.

Now to the point. How many waiting lines have we seen clamoring for instruction in orthodontia? How many postgraduate courses or study clubs ever offer instruction in orthodontia at this time? 
You say there is not the demand for this instruction; but why, then, is there not sufficient demand? Is it because the dental profession is being taught what little orthodontia it feels it requires for the most part in general practice, by spectacular advertising, propaganda calling attention to some particular type of appliance and the almost incredible and none-the-less impossible things which it will do all by itself if once set in motion?

Appliances are being advertised and claims made for them which are no less ludicrous to the trained man in orthodontia, than is the traditional cotton root canal filling, to the trained root canal man of today.

One appliance manufacturer, in exploiting the dental profession upon this subject, has addressed personal letters to members of state dental organizations, immediately subsequent to the state meeting, advising them with deep regret, that other duties prevented him from being able to attend the recent meeting and appear on the program to demonstrate his appliance before the organization, and so on and so forth.

Of course, all of this is amusing, to say the least; but, at the same time, this kind of propaganda is possible only because there is less actual information possessed by the general practitioner on the subject and methods of modern orthodontia than on any other branch of dentistry, hence misinformation is accepted by some as a substitute.

There is still another angle to the situation. The dentist many times starts a case of malocclusion because of his location. He may have no one to whom to refer his case. Lacking a thorough knowledge of orthodontia, he is looking for a short cut. He prefers to compromise and he excuses himself under the very popular delusion that the public is not willing to compensate him properly for highly specialized work. In this assumption, the dentist is entirely and grossly wrong, for as a matter of fact there is no better or more highly paid department of dentistry than the treatment of malocclusion. The compensation feature will not "hold water." If the dentist fails to be properly compensated for this work, it is either because he is unable to prove his case, or because he is not in a position to deliver results in orthodontia. Any individual who can afford an automobile all the way from a Ford to a Pierce Arrow can well afford and will arrange to have his children's mouths properly treated if the dentist is able to obtain results. Again, there is no more delightful or interesting work in the practice of dentistry, than that of orthodontia when practiced by modern methods.

There are many men who can promptly give the last word in conductive anesthesia, prosthesis, root canal technic, exodontia, or in fact any of the various specialties of dentistry, who will frankly admit that they know nothing about orthodontia, and rather pride themselves in knowing so little of the subject.

The fundamental principles of orthodontia and modern mechanical technic are badly needed by practically all men who have not been fortunate enough to secure special training. In turn, the public is badly in need of more orthodontists or at least more men who really understand the subject sufficiently to do good work for their patients. 
Again, we ask are the specialists derelict in their full duty to the dental profession in not making determined efforts to advance this specialty among the general practitioners and to dispense information to those who seek the truth, that being the real object of true science? There is a great tendency among orthodontists to take the view that it is useless to give papers or clinies before dental societies and this is proved by the fact that some specialists have stated that they would not give an orthodontic paper before a dental society. This is an attitude that will not do the dental profession any good and allows misinformation to take the place of proper instruction. Papers should be given before the dental societies, which will enlighten the dentist as to the possibilities of modern orthodontia and teach him enough of the mechanical principles so that he will not be the prey of every misleading appliance advertisement that may come before him. Clinics should be given featuring what can be done in given cases and the design of modern appliances demonstrated. By giving such instruction the specialists will be doing a good work for the dental profession and the public, as well as supplying a new impetus to the advancement of orthodontia as a science. 